\title{
miR-138 expression in oral herpes simplex and its effect on ICP0
}

\author{
XIAO YAN ${ }^{1}$, JING SUN ${ }^{2}$ and KUIFENG YUAN ${ }^{1}$ \\ Departments of ${ }^{1}$ Stomatology and ${ }^{2}$ Pharmacy, The Second Qilu Hospital of Shandong University, \\ Jinan, Shandong 250033, P.R. China
}

Received March 7, 2018; Accepted October 22, 2018

DOI: 10.3892/etm.2018.6912

\begin{abstract}
This study aimed to investigate the micro ribonucleic acid-138 (miR-138) expression in oral herpes simplex (HS) and its effect on the expression of herpes simplex virus type 1 (HSV-1) lytic gene trans-acting factor infected cell protein 0 (ICP0). Forty-five rat models with oral HS were successfully established (the observation group) and another 40 healthy rats were selected as the control group. The miR-138 expression in serum of rats in the two groups were detected by reverse transcription-quantitative polymerase chain reaction (RT-qPCR). 293T cells infected by HSV-1 were divided into Group A and Group B after 10 days of culture. Group A was transfected by miR-138 mimics and Group B was transfected by miR-138 complementary oligonucleotide inhibitor. The expression levels of miR-138 and ICP0 messenger RNA (mRNA) in the cells of the two groups were detected by RT-PCR, and the expression levels of ICP0 protein were detected by enzyme-linked immunosorbent assay (ELISA). A total of 85 rat models with oral HS were established in this study, but only 45 models were established successfully with a success rate of $56.25 \%$. The expression level of miR-138 in the rat serum in the observation group was higher than that in the control group $(\mathrm{P}<0.05)$. In addition, the expression level of ICP0 mRNA in Group A was lower than that in Group B $(\mathrm{P}<0.05)$. Moreover, the expression level of ICP0 protein in Group A was lower than that in Group B $(\mathrm{P}<0.05)$. Finally, the expression level of miR-138 in HSV was increased, suggesting that the expression of miR-138 may inhibit the expression of ICP0, thus preventing the duplication of HSV-1. Therefore, the expression of miR-138 may be used as a potential therapeutic target for HSV.
\end{abstract}

\section{Introduction}

Herpes simplex (HS) is a kind of infectious mucosa and skin disease caused by herpes simplex virus (HSV) and oral

Correspondence to: Dr Kuifeng Yuan, Department of Stomatology, The Second Qilu Hospital of Shandong University, 247 Beiyuan Street, Jinan, Shandong 250033, P.R. China

E-mail:krk7ry@163.com

Key words: miR-138, ICP0, HSV-1, rat models infection is mainly caused by HSV-1 $(1,2)$. HS is a worldwide health problem. It has been reported that there are approximately 150 million people who suffer from recurrent HS worldwide, and antibodies against HSV have been found in the serum of $90 \%$ research subjects, which suggested that these subjects used to or are still infected with $\operatorname{HSV}(3,4)$.

Micro ribonucleic acid (miR) is widely expressed in eukaryotic organisms and it regulates cell proliferation and apoptosis, participates in multiple pathophysiological processes and regulates cell differentiation $(5,6)$. Substantial research has shown that miR-138 can inhibit the expression of infected cell protein 0 (ICP0) $(4,7,8)$. ICP0 is a protein with strong functions. It is encoded by virus and can activate the expression of virus $\beta$ and gene $\gamma$ in turn. Besides, ICP0 also plays a vital role in activating the virus during the transition from latent period to lytic multiplication period $(9,10)$.

Therefore, the significance of miR-138 expression in HSV was studied in this experiment in which HSV rat models were established, miR-138 expression in serum was detected and miR-138 expression in $293 \mathrm{~T}$ cells infected by HSV was regulated.

\section{Materials and methods}

Research objects. Specific pathogen-free (SPF) SpragueDawley (SD) rats were purchased from the Laboratory Animal Center of Jilin University [certification number: SCXK(JI)2008-0004] and fed with LAD0011 feed (Trophic Animal Feed High-Tech Co., Ltd., Nantong, China). These SD rats, aged 7-8 weeks, weighing 200-240 g, were kept at temperature of $21 \pm 1.5^{\circ} \mathrm{C}$ and humidity of $40-60 \%$, with natural lighting and free access to food and water. The rearing cages and water bottles were changed twice a week.

The study was approved by the Ethics Committee of The Second Qilu Hospital of Shandong University (Jinan, China).

Establishment of SD rat models. The titre of Macaque HSV-1 (Shanghai Y-J Biological Technology Co., Ltd., Shanghai, China) was adjusted to TCID50 $10^{-5}$ before use. Hela cells were used to produce and detect the virus. After all rats were injected with pentobarbital sodium $(50 \mathrm{mg} / \mathrm{kg})$ by intraperitoneal injection for satisfactory general anesthesia, an operation was performed to make an incision of 'pound sign' on the surface of the right eye cornea of each rat with a $1 \mathrm{G}$ sterile needle under a microscope (Olympus Corporation, Tokyo, Japan). Then $10 \mu \mathrm{l}$ viral suspension (virus concentration of 
TCID50 $10^{-5}$ ) was dropped into the right eye cornea of each rat in the observation group and remained for $15 \mathrm{sec}$, and normal saline was dropped into the right eye of each rat in the control group. The eyelids of all the rats were massaged for fast absorption, and lincomycin hydrochloride and erythrocin were used to decrease inflammation after operation. Six days later, all rats with HSV were diagnosed via the method reported by Heiligenhaus et al (11).

Virus infection of 2937 cells. The construction and package of viral vectors were performed by Hunan Auragene Bioscience Corporation Inc. (Changsha, China). After the linearization of viral vectors via DNA Pac I enzyme, 293T cells (cat. no. CRL-11268; Bio-protocol LLC, Sunnyvale, CA, USA) were transfected using liposomes method (Xiamen Yanke Biotechnology Co., Ltd.). After $24 \mathrm{~h}$ of cultivation in Dulbecco's modified Eagle's medium (DMEM), polybrene was added to accelerate infection efficiency of the virus. Then the medium was replaced with fresh media containing miR-138 mimics (Group A) and miR-138 complementary oligonucleotide inhibitor (Group B), respectively, and cultivated for 2 weeks (replaced every $24 \mathrm{~h}$ ).

RNA extraction. The total RNA in serum and cells was extracted using TRIzol reagents and the operation was conducted in accordance with the instructions provided by Invitrogen; Thermo Fisher Scientific, Inc. (Waltham, MA, USA). The concentration and purity of the extracted RNA were analyzed with an ultraviolet spectrophotometer (Bio-Rad Laboratories, Inc., Hercules, CA, USA) and the completeness of RNA was analyzed by $3 \%$ agarose gel electrophoresis.

Synthesis of complementary DNA (cDNA). TaqMan ${ }^{\circledR}$ MicroRNA reverse transcription kit [Thermo Fisher Scientific (China) Co., Ltd., Shanghai, China] was used and the synthesis of cDNA via reverse transcription was conducted in accordance with the instructions. Reaction conditions are as follows: $37^{\circ} \mathrm{C}$ for $45 \mathrm{~min}$ and $95^{\circ} \mathrm{C}$ for $5 \mathrm{~min}$. The reaction product was preserved at $-20^{\circ} \mathrm{C}$.

Reverse transcription-quantitative polymerase chain reaction (RT-qPCR). The $25 \mu 1$ reaction system was: pre-degeneration at $95^{\circ} \mathrm{C}$ for $5 \mathrm{~min}$, degeneration at $95^{\circ} \mathrm{C}$ for $30 \mathrm{sec}$, annealing at $60^{\circ} \mathrm{C}$ for $45 \mathrm{sec}$ and extension at $72^{\circ} \mathrm{C}$ for $3 \mathrm{~min}$, a total of 35 cycles, followed by extension at $72^{\circ} \mathrm{C}$ for $5 \mathrm{~min}$. ABI Prism 7900PCR instrument was used in PCR. miR-138, forward, 5'-GTATTG ACTAGATTAATCACTGT-3' and reverse, 5'-CTCGCTTCG GCAGCACA-3'; ICP0 mRNA, forward, 5'-TCTCGAACAGTT CCGTGTCCGT-3' and reverse, 5'-TCTCCGCATCACCACAG AAG-3'. U6 (Shanghai Meixuan Biological Science and Technology Ltd., Shanghai, China) was used as an internal reference for reaction: Forward, 5'-CTCGCT TCGGCAGCACA-3' and reverse, 5'-TCTCCGCATCACCACAGAAG-3'. The experiment was repeated for all the samples in 3 wells and the results were analyzed by $2^{-\Delta \Delta \mathrm{Cq}}$ method (12).

Observation indexes. The peripheral blood of rats in the observation and control groups were collected by cutting the tail at three different time-points $(n=15)$, respectively: at the same day of diagnosis with HS (day 1), at 7 days (day 7) and 14 days (day 14) after diagnosis with HS. After completion, the rats were anesthetized by intraperitoneal injection of pentobarbital sodium (100 mg/kg, Shanghai Rongbai Biological Technology Co., Ltd.) and sacrificed by cervical dislocation. The expression levels of miR-138 in serum and the expression levels of miR-138 and ICP0 mRNA in cells in the two groups were detected via RT-qPCR, and the expression levels of ICP0 (mouse anti-rat HSV1 ICP0 monoclonal antibody; 1:3,000, cat. no. ab6513; Abcam, Cambridge, MA, USA) protein were detected via enzyme-linked immunosorbent assay (ELISA).

Statistical analysis. Statistical Product and Service Solutions (SPSS) 19.0 software (AsiaAnalytics Formerly SPSS China) was used. Chi-square test was used for the comparison of rates. Measurement data were presented as (mean \pm SD), the nonparametric K-S test was used for the comparison between the two groups and t-test was used for the intra-group comparison at different time-points. The correlation of miR-138 with ICP0 mRNA was analyzed by logistic regression analysis. $\mathrm{P}<0.05$ suggested that the difference was statistically significant.

\section{Results}

The success rate of model establishment was 56.25\%. Fortyfive SD rat models with HS were established successfully in this study, 7 rats died and 28 rat models did not qualify. There were 26 male and 19 female SD rats in the observation group with a mean age of $8.2 \pm 0.5$ weeks, a mean length of $17.9 \pm 1.1 \mathrm{~cm}$ and a mean weight of $221.4 \pm 15.3 \mathrm{~g}$. There were 23 male and 17 female SD rats in the control group with a mean age of $8.5 \pm 0.7$ weeks, a mean length of $18.2 \pm 1.4 \mathrm{~cm}$ and a mean weight of $215.4 \pm 13.2 \mathrm{~g}$. The rats in both groups were given free access to food, water and natural lighting. No differences were found in the sex, age and weight of rats between the two groups $(\mathrm{P}>0.05)$ (Table I).

RT-PCR amplification results of miR-138 in rat serum and $293 T$ cells. RT-PCR amplification of miR-138 and ICP0 mRNA in rat serum and in $293 \mathrm{~T}$ cells were conducted. The statistical analysis on the detection results showed that differences were found in the expression level of miR-138 at the same period between the two groups $(\mathrm{P}=0.035, \mathrm{P}=0.041)$, and the expression level in rat serum in the observation group was significantly lower than that in the control group. The rats were sacrificed at different time-points. There was no obvious change in the expression level of miR-138 in rat serum in the control group, while the expression level of miR-138 in rat serum in the observation group was gradually decreased over time. The expression level of miR-138 in rat serum at day 14 was significantly lower than that at day 1 . Then, the expression level of miR-138 in $293 \mathrm{~T}$ cells was analyzed and the result showed that the expression level of miR-138 in Group A was significantly higher than that in Group B $(\mathrm{P}<0.05)$ (Table II).

RT-PCR amplification results of ICPO mRNA in 293 cells. RT-PCR amplification of ICP0 mRNA in 293T cells were conducted, and the statistical analysis on the detection results showed that the expression level of ICP0 mRNA in Group A was significantly lower than that in Group B $(\mathrm{P}<0.05)$ (Fig. 1). 
Table I. General data of rats between the two groups.

\begin{tabular}{lccr}
\hline Variables & Observation group $(\mathrm{n}=45)$ & Control group $(\mathrm{n}=40)$ & $\mathrm{t} / \chi^{2}$ test \\
\hline Age (weeks) & $8.2 \pm 0.5$ & $8.5 \pm 0.7$ & 2.64 \\
Sex (male/female) & $26 / 19$ & $23 / 17$ & 0.785 \\
Length (cm) & $17.9 \pm 1.1$ & $18.2 \pm 1.4$ & 0.693 \\
Weight $(\mathrm{g})$ & $221.4 \pm 15.3$ & $215.4 \pm 13.2$ & 0.712 \\
\hline
\end{tabular}

Table II. Analysis on the expression levels of miR-138 in rat serum and 293T cells.

\begin{tabular}{llcrr}
\hline Variables & & Observation group & Control group & t-test \\
\hline Rat serum & $\mathrm{d} 1(\mathrm{n}=15)$ & 1.729 & 2.617 & 3.44 \\
& $\mathrm{~d} 7(\mathrm{n}=15)$ & 1.233 & 2.543 & 0.035 \\
& $\mathrm{~d} 14(\mathrm{n}=15)$ & $0.475^{\mathrm{a}}$ & 2.596 & 0.011 \\
& & Group A & Group B & 14.96 \\
293T cells & 2.135 & 0.032 & 15.44 \\
\hline
\end{tabular}

${ }^{\mathrm{a}}$ The expression level of miR-138 is lower than that at $\mathrm{d} 1(\mathrm{P}=0.05)$.

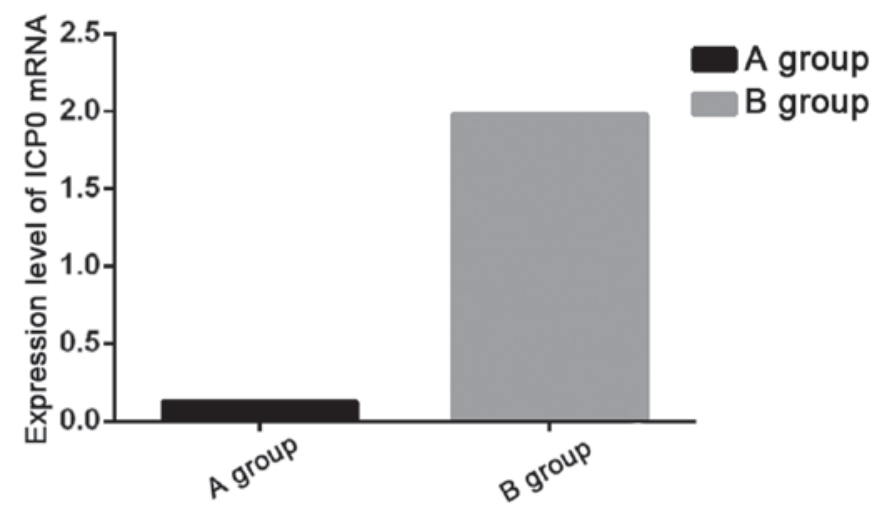

Figure 1. RT-qPCR amplification results of ICPO mRNA in 293T cells.

ELISA detection results of ICPO in 2937 cells. The expression levels of ICP0 protein in 293T cells were detected by ELISA, and the statistical analysis on the detection results showed that the expression level of ICP0 protein in Group A was significantly lower than that in Group B $(\mathrm{P}<0.05)$ (Fig. 2).

Logistic regression analysis. The correlation of $\mathrm{miR}-138$ with ICP0 mRNA was analyzed by logistic regression analysis, and the result showed that the expression level of miR-138 was negatively correlated with that of ICP0 mRNA ( $r=-0.667$, $\mathrm{P}=0.006$ ).

\section{Discussion}

HSV has a very high infection rate in the world. According to statistics, $90 \%$ of the individuals have had a history of HSV (3). When the immunity in human body is reduced, the expression of latent HSV gene starts to reduplicate and enter into lytic proliferation period, resulting in severe epithelial

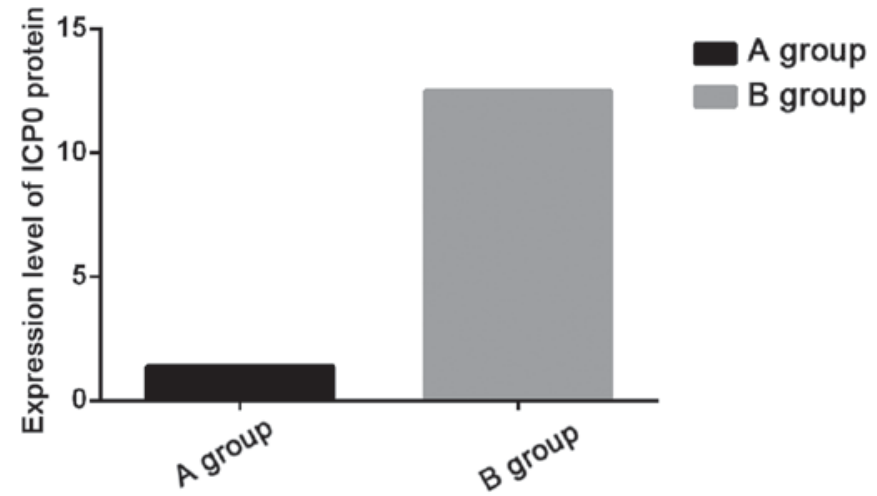

Figure 2. Enzyme-linked immunosorbent assay (ELISA) detection results of ICP0 in 293 T cells.

herpes $(13,14)$. A lot of research has been conducted on HSV from the perspective of molecular biology $(15,16)$. Research has shown that miR-138 can inhibit the expression of ICP0 $(4,7,8)$, and ICP0 plays a vital role in HSV. Therefore, the expression level of miR-138 was investigated to study the value of its expression.

A total of 45 rat models with HS were established in this study. After the models were confirmed to be established successfully, the rats were sacrificed by cutting tail at day 1 , 7 and 14, and then the serum was collected. The RT-PCR amplification results of miR-138 in the rat serum showed that the expression level of miR-138 in the serum was gradually decreased with the extension of the course of disease in HS rats, and the expression level of miR-138 at day 14 was decreased to 0.475 which had a significant difference from that at day 1 (1.729) $(\mathrm{P}<0.05)$. miR-138 is a neuron-specific microRNA. It was (17) found that the decrease in the expression of miR-138 can make patients with latent HSV enter into lytic proliferation period and thus, increase the mortality rate of patients. Guo 
and Steitz (18) also reported in their study that miR-138 can inhibit the expression of ICP0 protein and produce a longer latent period of HSV-1, which is similar to the results in this study. However, as this study was based on animal models and rats died artificially, the change in the mortality rate of patients with HSV and the influence of miR-138 on the latent period of HSV-1 cannot be explored in this study. Yet, they will be further clarified in our future studies.

The change in the expression levels of ICP0 was also investigated in this study through the construction of 293T cells infected by HSV-1 and the regulation of the expression levels of miR-138. The results showed that the expression levels of miR-138 were successfully regulated via miR-138 mimics and miR-138 complementary oligonucleotide inhibitor, and significant difference was found between the two groups. The detection results of ICP0 indicated that the expression levels of ICP0 mRNA and ICP0 protein in 293T cells after the upregulation of miR-138 via miR-138 mimics were significantly lower than those after the downregulation of miR-138 via inhibitor, which indicated that miR-138 can regulate the expression of ICP0 in cells. Moreover, the logistic regression analysis found that miR-138 was negatively correlated with ICP0. Therefore, it can be speculated that the expression level of miR-138 in patients with latent HSV-1 will be decreased with the extension of latent period. In addition, with the stimulation of environment and the decline in immune function, HSV-1 latent period will transform into lytic multiplication period and thus result in HSV with symptoms such as herpes. The results of Boutell and Everett (9) indicated that ICP0 is a protein essential for the re-activation of HSV-1, and the study of Pare and Sullivan (17) also demonstrated that the expression level of ICP0 was significantly decreased by miR-138 and this influence is specific. This result can be further verified in the future through high-throughput sequencing analysis on patients with HS.

The present study was based on experimental animal models and cell strain, so the ethical problem was avoided. However, the mRNA used in this study had been preserved at $-20^{\circ} \mathrm{C}$, which may influence the activity of miR-138 and ICP0 mRNA. Therefore, the experimental results in this study need to be verified by more experiments and conclusions also need to be supported by large sample data.

In conclusion, the increase in the expression level of miR-138 in patients with HSV can inhibit the expression of ICPO and thus, it prevents the duplication of HSV-1. Therefore, the expression level of miR-138 may be used as a potential therapeutic target for oral HS.

\section{Acknowledgements}

Not applicable.

\section{Funding}

No funding was received.

\section{Availability of data and materials}

The datasets used and/or analyzed during the present study are available from the corresponding author on reasonable request.

\section{Authors' contributions}

XY drafted this manuscript and performed PCR. JS contributed to the establishment of SD rat models. KY helped with virus infection of $293 \mathrm{~T}$ cells. All authors have read and approved the final manuscript.

\section{Ethics approval and consent to participate}

The study was approved by the Ethics Committee of The Second Qilu Hospital of Shandong University (Jinan, China).

\section{Patient consent for publication}

Not applicable.

\section{Competing interests}

The authors declare that they have no competing interests.

\section{References}

1. Armangue T, Leypoldt F, Málaga I, Raspall-Chaure M, Marti I, Nichter C, Pugh J, Vicente-Rasoamalala M, Lafuente-Hidalgo M, Macaya A, et al: Herpes simplex virus encephalitis is a trigger of brain autoimmunity. Ann Neurol 75: 317-323, 2014.

2. Cockle JV, Ilett E, Brüningrichardson A, Scott K, Picton S, Short S and Melcher A: OP03 oncolytic herpes simplex virus inhibits paediatric high grade glioma and diffuse intrinsic pontine glioma migration and invasion; Mechanism and potential for clinical application. Neuro-Oncology 17: viii16.3-viii16, 2015.

3. Looker KJ, Magaret AS, Turner KM, Vickerman P, Gottlieb SL and Newman LM: Correction: Global estimates of prevalent and incident herpes simplex virus type 2 infections in 2012. PLoS One 10: e0128615, 2015.

4. Pan D, Flores O, Umbach JL, Pesola JM, Bentley P, Rosato PC, Leib DA, Cullen BR and Coen DM: A neuron-specific host microRNA targets herpes simplex virus-1 ICP0 expression and promotes latency. Cell Host Microbe 15: 446-456, 2014.

5. Ha M and Kim VN: Regulation of microRNA biogenesis. Nat Rev Mol Cell Biol 15: 509-524, 2014.

6. Lingam S, Beta M, Dendukuri D and Krishnakumar S: A focus on microfluidics and nanotechnology approaches for the ultra sensitive detection of microRNA. MicroRNA 3: 18-28, 2014.

7. Coleman JR, Papamichail D, Skiena S, Futcher B, Wimmer E and Mueller S: Virus attenuation by genome-scale changes in codon pair bias. Science 320: 1784-1787, 2008.

8. Sharma S, Hussain S, Soni K, Singhal P, Tripathi R, Ramachandran VG, Sharma S, Das S, Pillai B and Bharadwaj M: Novel MicroRNA signatures in HPV-mediated cervical carcinogenesis in Indian women. Tumour Biol 37: 4585-4595, 2016.

9. Boutell C and Everett RD: Regulation of alphaherpesvirus infections by the ICP0 family of proteins. J Gen Virol 94: 465-481, 2013.

10. Orzalli MH, Broekema NM and Knipe DM: Relative contributions of herpes simplex virus 1 ICP0 and VHS to loss of cellular IFI16 vary in different human cell types. J Virol 90: 8351-8359, 2016.

11. Heiligenhaus A, Li HF, Yang Y, Wasmuth S, Steuhl KP and Bauer D: Transplantation of amniotic membrane in murine herpes stromal keratitis modulates matrix metalloproteinases in the cornea. Invest Ophthalmol Vis Sci 46: 4079-4085, 2005.

12. Livak KJ and Schmittgen TD: Analysis of relative gene expression data using real-time quantitative PCR and the 2(-Delta Delta C(T)) method. Methods 25: 402-408, 2001.

13. Hacohen Y, Deiva K, Pettingill P, Waters P, Siddiqui A, Chretien P, Menson E, Lin JP, Tardieu M, Vincent A, et al: $\mathrm{N}$-methyl-D-aspartate receptor antibodies in post-herpes simplex virus encephalitis neurological relapse. Mov Disord 29: 90-96, 2014. 
14. Bradley H, Markowitz LE, Gibson T and McQuillan GM: Seroprevalence of herpes simplex virus types 1 and 2 - United States, 1999-2010. J Infect Dis 209: 325-333, 2014.

15. Mohammad SS, Sinclair K, Pillai S, Merheb V, Aumann TD, Gill D, Dale RC and Brilot F: Herpes simplex encephalitis relapse with chorea is associated with autoantibodies to N-Methyl-D-aspartate receptor or dopamine-2 receptor. Mov Disord 29: 117-122, 2014

16. Orzalli MH, Broekema NM, Diner BA, Hancks DC, Elde NC Cristea IM and Knipe DM: cGAS-mediated stabilization of IFI16 promotes innate signaling during herpes simplex virus infection. Proc Natl Acad Sci USA 112: E1773-E1781, 2015.
17. Pare JM and Sullivan CS: A host MicroRNA brokers truce with HSV-1. Cell Host Microbe 15: 395-397, 2014.

18. Guo YE and Steitz JA: Virus meets host microRNA: The destroyer, the booster, the hijacker. Mol Cell Biol 34: 3780-3787, 2014.

This work is licensed under a Creative Commons Attribution-NonCommercial-NoDerivatives 4.0 International (CC BY-NC-ND 4.0) License. 